\title{
The association between pre-miR-27a rs895819 polymorphism and myocardial infarction risk in a Chinese Han population
}

\author{
Meng-yun Cai ${ }^{1,2 \dagger}$, Jie Cheng ${ }^{1,2,3 \dagger}$, Meng-yuan Zhou ${ }^{1,2}$, Li-li Liang ${ }^{1,2}$, Si-min Lian ${ }^{1,2}$, Xiao-shan Xie ${ }^{1,2}$, Shun Xu ${ }^{1,2}$, \\ Xinguang Liu ${ }^{1,2,4}$ and Xing-dong Xiong ${ }^{1,2,4^{*}}$
}

\begin{abstract}
Background: Accumulating evidences have shown that miRNAs are directly or indirectly involved in a variety of biological processes, and closely associated with diverse human diseases, including cardiovascular diseases. SNPs locating within pri/pre-miRNA can affect miRNA processing and binding ability of target genes. MiR-27a, miR-26a-1 miR-100, miR-126 and miR-218 were reported to be associated with pathogenesis of myocardial infarction (MI). Here we aimed to evaluate the potential association of five polymorphisms in these pri/pre-miRNAs with individual susceptibility to MI in a Chinese Han population.
\end{abstract}

Methods: Genotyping was performed in $287 \mathrm{Ml}$ cases and 646 control subjects using polymerase chain reactionligase detection reaction (PCR-LDR) method. The association of these SNPs with MI risk was performed with SPSS software.

Results: In a logistic regression analysis, we found that $A G$ heterozygote $(\mathrm{OR}=0.40,95 \% \mathrm{Cl}=0.21-0.76, \mathrm{~Pa}=0.005)$ or AA homozygote $(\mathrm{OR}=0.40,95 \% \mathrm{Cl}=0.22-0.75, \mathrm{~Pa}=0.004)$ of pre-miR-27a rs895819 had a reduced susceptibility to $\mathrm{MI}$ in comparison with $\mathrm{GG}$ homozygote. Similarly, a reduced risk of $\mathrm{Ml}$ was detected when the $\mathrm{AG}$ and $\mathrm{AA}$ genotypes were combined $(\mathrm{OR}=0.40,95 \% \mathrm{Cl}=0.22-0.74, \mathrm{~Pa}=0.003)$. However, no significant association between primiR-26a-1 pri-miR-100, pri-miR-126 and pri-miR-218 polymorphisms and MI risk was observed under the allelic and established genetic models. Further stratified analysis of pre-miR-27a rs895819 revealed a more significant association of AG + AA genotypes with MI risk among younger, male and smoking subjects. Interestingly, AG and AA genotypes of the rs895819 polymorphism conferred about $0.17 \mathrm{mmol} / \mathrm{L}$ and $0.18 \mathrm{mmol} / \mathrm{L}$ increase in $\mathrm{HDL}-\mathrm{C}$ levels compared to GG genotype.

Conclusions: Our findings suggest that the pre-miR-27a rs895819 polymorphism is associated with MI susceptibility in the Chinese Han population, which probably due to influence the HDL-C levels.

Keywords: miR-27a, Single nucleotide polymorphism, rs895819, Myocardial infarction, Disease susceptibility

\section{Background}

Myocardial infarction (MI) is a leading cause of death and disability, which has posed major challenges for China's health system [1-3]. Previously established risk factors for MI including hypertension, diabetes, physical

\footnotetext{
* Correspondence: xiongxingdong@126.com

${ }^{\dagger}$ Equal contributors

'Institute of Aging Research, Guangdong Medical University, Xin Cheng Avenue 1\#, Songshan Lake, Dongguan 523808, People's Republic of China ${ }^{2}$ Guangdong Provincial Key Laboratory of Medical Molecular Diagnostics, Guangdong Medical University, Dongguan, People's Republic of China

Full list of author information is available at the end of the article
}

inactivity, smoking, alcohol intake, abnormal lipids, abdominal obesity, high-risk diet and psychosocial stress factors [4]. However, these modifiable factors can not readily explain overall $\mathrm{MI}$ incidence, thus hereditary factors must be involved. It is believed that complex interaction between susceptibility genes and environmental risk factors contributes to the occurrence of coronary artery disease $(\mathrm{CAD})$ and its extreme manifestation of $\mathrm{MI}$, and single nucleotide polymorphisms (SNPs), as the most common genetic variation was much accounted for $[5,6]$. 
MicroRNAs (miRNAs) are a class of small non-coding RNA molecules with a length of 18 25 nucleotides. Typically, miRNAs function as the suppressors by guiding the miRNA-induced silencing complex (miRISC) to the 3' untranslated regions (3'UTRs) of mRNA targets. Accumulating evidences have shown that miRNAs are directly or indirectly involved in a variety of biological processes, and closely associated with diverse human diseases, including cancer [7], Alzheimer's disease [8] and cardiovascular diseases $[9,10]$. MiRNA biogenesis begins with transcription by RNA polymerase II to create the primary miRNA (pri-miRNA). Then miRNA precursor (pre-miRNA) is generated from pri-miRNA by the nuclear ribonuclease (RNase) III DROSHA and the RNA-binding protein DCGR8. Ultimately, the precursor is exported out of the nucleus and processed the precursor into the mature miRNA by a RNase III enzyme, Dicer [11]. Biogenesis of miRNA could be regulated at each of these steps. Previous studies have demonstrated that SNP locating within pri-miRNAs or pre-miRNAs can affect miRNA processing and binding ability of target genes [12].

According to previous studies, miR-27a, miR-26a-1 miR-100, miR-126 and miR-218 were reported to be associated with pathogenesis of MI [13-17]. In this study, we conducted a large-scale case-control association study in $287 \mathrm{MI}$ patients and 646 controls to investigate the correlation between five polymorphisms in these pri/ pre-miRNAs and MI susceptibility, and revealed that the pre-miR-27a rs 895819 polymorphism is associated with MI susceptibility in the Chinese Han population, which probably due to influence the HDL-C levels.

\section{Methods}

\section{Study population}

In this case-control study, $287 \mathrm{MI}$ patients and 646 control subjects were consecutively recruited from the First People's Hospital of Foshan (Foshan, China) and the Affiliated Hospital of Guangdong Medical University (Zhanjiang, China) from March 2011 to October 2015. We consulted each subject for the genetic relatedness information and excluded the individuals related to the subjects who had enrolled in this study. Therefore, all subjects were genetically unrelated Han Chinese, as describe before [18]. The diagnosis of MI was based on unstable angina and typical electrocardiographic changes such as significant ST-segment-T wave (ST-T) changes, new left bundle branch block, development of pathological Q waves, also on increases in the serum cardiac markers, such as creatinine kinase, aspartate aminotransferase, lactate dehydrogenase and troponin $\mathrm{T}$. The diagnosis was further confirmed by the identification of the responsible stenosis in any of the major coronary arteries or in the left main trunk by coronary angiography. All the MI patients were newly diagnosed and previously untreated. A total of 646 controls were judged to be free of MI by questionnaires, medical history, clinical examination and electrocardiography. Besides, we excluded subjects with chronic ischemic heart disease from the control group by electrocardiogram, treadmill exercise test and coronary computed tomography angiography. The diagnosis of hypertension was established if patients were on antihypertensive medication or if the mean of 3 measurements of systolic blood pressure (SBP) above $140 \mathrm{mmHg}$ or diastolic blood pressure (DBP) above $90 \mathrm{mmHg}$, respectively. Diabetes mellitus was defined as fasting blood glucose (FBG) above $7.0 \mathrm{mmol} / \mathrm{L}$ or use anti-diabetic drug therapies. Individuals that smoked once a day for over 1 year were defined as smokers. Hyperlipidemia was defined as serum total cholesterol (TC) concentration $>5.72 \mathrm{mmol} / \mathrm{L}$ or triglyceride (TG) concentration $>1.70 \mathrm{mmol} / \mathrm{L}$ or use of lipid-lowering therapy. In addition, individuals with medication treatment (statins, fibrates, diuretics, betablockers and hormones), congestive heart failure, peripheral vascular disease, rheumatic heart disease, pulmonary heart disease, chronic kidney, hepatic disease or any malignancy were excluded by questionnaires and medical history from this study. Information on demographic data and MI-related risk factors was collected by a structured questionnaire after obtaining the informed consent. This study was approved by the Medical Ethics Committee of the First People's Hospital of Foshan and the Affiliated Hospital of Guangdong Medical University.

\section{Biochemical parameters analysis}

After an informed consent, $2 \mathrm{ml}$ of peripheral blood sample was collected from each subject for later DNA extraction and genotyping assays. All of the participants of MI and control groups were required to blood taken in the morning and after fasted for at least $8 \mathrm{~h}$. The levels of plasma total cholesterol (TC), triglyceride (TG), high-density lipoprotein cholesterol (HDL-C) and lowdensity lipoprotein cholesterol (LDL-C) were measured enzymatically using a chemistry analyzer (Olympus, Japan). Glucose was analyzed by the glucose oxidase method with an Abbott V/P Analyzer (Abbott Laboratories, USA).

\section{DNA extraction}

Genomic DNA was isolated from peripheral whole blood using blood DNA extraction kit (TianGen Biotech, Beijing, China) according to the manufacturer's instructions. All DNA samples were dissolved in water and stored at $-20{ }^{\circ} \mathrm{C}$ until use. 


\section{Genotyping}

SNP genotyping were performed utilizing polymerase chain reaction-ligase detection reaction (PCR-LDR) method (Shanghai Biowing Applied Biotechnology Company), as described in our previous study [18]. The sequence of primers and probes were showed in Additional file 1: Table S1.

\section{Statistical analysis}

Hardy-Weinberg equilibrium was tested using the goodness-of-fit $X^{2}$ test among the control subjects. Qualitative variables were expressed as percentages and quantitative variables were expressed as mean \pm standard deviation (SD). The differences of the demographic characteristics between the cases and controls were estimated using the $\chi^{2}$ test or Student's $t$ test for categorical variables and continuous variables respectively. Association between rs895819 and the risk of MI was evaluated using logistic regression analysis. The odds ratios (ORs) and 95\% confidence intervals (CIs) for the effect of rs895819 on MI risk adjusted by age, sex, smoking, drinking, hypertension, diabetes and hyperlipidemia. One-way analysis of variance (ANOVA) was performed to analyze the association between SNP and lipid profiles. All the analyses were performed using the SPSS software (version 21), and $P$ value of less than 0.05 was used as the criterion of statistical significance.

\section{Results}

\section{Association of pri/pre-miRNA polymorphisms with the risk of MI}

Two hundred eighty seven MI cases and 646 control subjects were included in the current study. Basic characteristics of the study objects were presented in Table 1. Compared with control subjects, the MI cases had higher rate of male, smoking and alcohol consumers, prevalence of hypertension, hyperlipidemia and diabetes, and higher levels of fasting plasma glucose (FBG), Triglycerides (TG), and LDL-C, but lower HDLC. These dataset demonstrated that the male gender, alcohol intake, smoking, hypertension, diabetes and dyslipidemia were the important and well-known risk factors for developing MI in this study.

The observed allele and genotype distributions of these pri/pre-miRNA polymorphisms in the cases and controls were listed in Table 2. The observed genotype distribution in the controls did not deviate from the HardyWeinberg equilibrium $(P>0.05)$, providing no evidence of population stratification within the dataset.

After adjustment for possible confounding factors (age, sex, smoking, drinking, hypertension, diabetes and hyperlipidemia), the frequencies of the GG, AG, and AA genotypes of pre-miR27a rs 895819 were $10.1 \%$, 35.5\%, $54.4 \%$ respectively among the cases, and 5.7\%, 38.9\%, $55.4 \%$ respectively among the controls. Subjects carrying AG heterozygote $\left(\mathrm{OR}=0.40,95 \% \mathrm{CI}=0.21-0.76, P_{a}=\right.$ $0.005)$ or AA homozygote $(\mathrm{OR}=0.40,95 \% \mathrm{CI}=0.22$ $\left.0.75, P_{a}=0.004\right)$ had a reduced susceptibility of MI in comparison with GG homozygote (Table 2). Similarly, a trend of the reduced MI risk was detected when the AG and $\mathrm{AA}$ genotypes were combined $(\mathrm{OR}=0.40,95 \% \mathrm{CI}=$ 0.22-0.74, $P_{a}=0.003$, Table 2). However, no significant association between pri-miR-26a-1 pri-miR-100, primiR-126 and pri-miR-218 polymorphisms and MI risk was observed under the allelic and established genetic models (Table 2).

Table 1 The characteristics of Ml cases and controls

\begin{tabular}{|c|c|c|c|}
\hline Variable & Cases $(n=287)$ & Controls $(n=646)$ & $P$-value ${ }^{a}$ \\
\hline Age (years) & $61.82 \pm 11.98$ & $61.44 \pm 12.28$ & 0.660 \\
\hline Sex (male) & $222(77.4 \%)$ & $374(57.9 \%)$ & $<0.001$ \\
\hline Smoking & $171(59.6 \%)$ & $164(25.4 \%)$ & $<0.001$ \\
\hline Drinking & 77 (26.8\%) & $91(14.1 \%)$ & $<0.001$ \\
\hline Hypertension & $182(63.4 \%)$ & $227(35.1 \%)$ & $<0.001$ \\
\hline Diabetes & $137(47.7 \%)$ & $105(16.3 \%)$ & $<0.001$ \\
\hline Hyperlipidemia & $203(70.7 \%)$ & $238(36.8 \%)$ & $<0.001$ \\
\hline Systolic BP (mm Hg) & $140.18 \pm 19.18$ & $132.20 \pm 18.73$ & $<0.001$ \\
\hline Diastolic BP (mm Hg) & $75.67 \pm 11.53$ & $72.73 \pm 10.39$ & $<0.001$ \\
\hline $\mathrm{FPG}(\mathrm{mmol} / \mathrm{L})$ & $6.63 \pm 1.73$ & $5.80 \pm 1.91$ & $<0.001$ \\
\hline Triglycerides (mmol/L) & $2.05 \pm 0.96$ & $1.48 \pm 0.80$ & $<0.001$ \\
\hline Total cholesterol (mmol/L) & $4.71 \pm 1.22$ & $4.62 \pm 1.14$ & 0.305 \\
\hline LDL cholesterol (mmol/L) & $3.04 \pm 0.97$ & $2.63 \pm 0.92$ & $<0.001$ \\
\hline HDL cholesterol (mmol/L) & $1.19 \pm 0.39$ & $1.38 \pm 0.67$ & $<0.001$ \\
\hline
\end{tabular}

${ }^{\mathrm{a}}$ Two-sided chi-square test or independent-samples $t$-test

${ }^{b} P$ values under 0.05 were indicated in bold font 
Table 2 Multivariate associations of the pre-miR-27a rs895819 with the risk of MI

\begin{tabular}{|c|c|c|c|c|c|}
\hline \multirow[t]{2}{*}{ Model } & \multirow[t]{2}{*}{ Genotype } & \multirow{2}{*}{$\begin{array}{l}\text { Cases }(n=287) \\
\text { No. }(\%)\end{array}$} & \multirow{2}{*}{$\begin{array}{l}\text { Controls }(n=646) \\
\text { No. }(\%)\end{array}$} & \multirow[t]{2}{*}{$\mathrm{OR}(95 \% \mathrm{Cl})^{\mathrm{a}}$} & \multirow[t]{2}{*}{$p^{a}$} \\
\hline & & & & & \\
\hline \multicolumn{6}{|c|}{ pre-miR-27a rs895819 HWE ${ }^{\mathrm{b}}: 0.4179$} \\
\hline \multirow[t]{2}{*}{ Allele } & G & $160(27.9)$ & $325(25.2)$ & 1.00 & \\
\hline & A & $414(72.1)$ & $967(74.8)$ & $0.77(0.60-1.01)$ & 0.055 \\
\hline \multirow[t]{3}{*}{ Genotype } & GG & $29(10.1)$ & $37(5.7)$ & 1.00 & \\
\hline & $A G$ & $102(35.5)$ & $251(38.9)$ & $0.40(0.21-0.76)$ & 0.005 \\
\hline & AA & $156(54.4)$ & $358(55.4)$ & $0.40(0.22-0.75)$ & 0.004 \\
\hline \multirow[t]{2}{*}{ Dominant } & $A G+G G$ & $288(44.6)$ & $131(45.6)$ & 1.00 & \\
\hline & AA & $156(54.4)$ & $358(55.4)$ & $0.86(0.62-1.21)$ & 0.389 \\
\hline \multirow[t]{2}{*}{ Recessive } & GG & $29(10.1)$ & $37(5.7)$ & 1.00 & \\
\hline & $A G+A A$ & $258(89.9)$ & $609(94.3)$ & $0.40(0.22-0.74)$ & 0.003 \\
\hline \multicolumn{6}{|c|}{ pri-miR-26a-1 rs7372209 HWE: 0.7195} \\
\hline \multirow[t]{2}{*}{ Allele } & C & $433(75.4)$ & $980(75.9)$ & 1.00 & \\
\hline & $\mathrm{T}$ & $141(24.6)$ & $312(24.1)$ & $0.98(0.74-1.29)$ & 0.879 \\
\hline \multirow[t]{3}{*}{ Genotype } & $\pi$ & $16(5.6)$ & $36(5.6)$ & 1.00 & \\
\hline & $\mathrm{CT}$ & $109(38.0)$ & $240(37.2)$ & $1.26(0.58-2.76)$ & 0.556 \\
\hline & $\mathrm{CC}$ & $162(56.4)$ & $370(57.3)$ & $1.21(0.57-2.60)$ & 0.619 \\
\hline \multirow[t]{2}{*}{ Dominant } & $\mathrm{CC}$ & $162(56.4)$ & $370(57.3)$ & 1.00 & \\
\hline & $C T+T$ & $125(43.6)$ & $276(42.7)$ & $1.01(0.72-1.42)$ & 0.947 \\
\hline \multirow[t]{2}{*}{ Recessive } & $\pi$ & $16(5.6)$ & $36(5.6)$ & 1.00 & \\
\hline & $C T+C C$ & $271(94.4)$ & $610(94.4)$ & $1.23(0.58-2.61)$ & 0.585 \\
\hline \multicolumn{6}{|c|}{ pri-miR-100 rs 1834306 HWE: 0.2017} \\
\hline \multirow[t]{2}{*}{ Allele } & C & $341(59.4)$ & $742(57.4)$ & 1.00 & \\
\hline & $\mathrm{T}$ & $233(40.6)$ & $550(42.6)$ & $0.97(0.77-1.23)$ & 0.816 \\
\hline \multirow[t]{3}{*}{ Genotype } & $\pi$ & $45(15.7)$ & $125(19.3)$ & 1.00 & \\
\hline & $\mathrm{CT}$ & $143(49.8)$ & $300(46.4)$ & $1.28(0.80-2.05)$ & 0.303 \\
\hline & $\mathrm{CC}$ & 99 (34.5) & $221(34.2)$ & $1.13(0.69-1.85)$ & 0.628 \\
\hline \multirow[t]{2}{*}{ Dominant } & $\pi$ & $45(15.7)$ & $125(19.3)$ & 1.00 & \\
\hline & $C T+C C$ & $242(84.3)$ & $521(80.7)$ & $1.22(0.78-1.90)$ & 0.391 \\
\hline \multirow[t]{2}{*}{ Recessive } & $\mathrm{CC}$ & $99(34.5)$ & $221(34.2)$ & 1.00 & \\
\hline & $C T+\pi$ & $188(65.5)$ & $425(65.8)$ & $1.06(0.75-1.51)$ & 0.733 \\
\hline \multicolumn{6}{|c|}{ pri-miR-126 rs4636297 HWE: 0.4457} \\
\hline \multirow[t]{2}{*}{ Allele } & G & $497(86.6)$ & $1106(85.6)$ & 1.00 & \\
\hline & A & $77(13.4)$ & $186(14.4)$ & $0.95(0.68-1.33)$ & 0.755 \\
\hline \multirow[t]{3}{*}{ Genotype } & GG & $216(75.3)$ & $471(72.9)$ & 1.00 & \\
\hline & $A G$ & $65(22.6)$ & $164(25.4)$ & $1.01(0.69-1.48)$ & 0.951 \\
\hline & AA & $6(2.1)$ & $11(1.7)$ & $1.44(0.41-5.10)$ & 0.569 \\
\hline Dominant & $\mathrm{AG}+\mathrm{GG}$ & $281(97.9)$ & $635(98.3)$ & 1.00 & \\
\hline & AA & $6(2.1)$ & $11(1.7)$ & $1.44(0.41-5.07)$ & 0.571 \\
\hline Recessive & GG & $216(75.3)$ & $471(72.9)$ & 1.00 & \\
\hline & $A G+A A$ & $71(24.7)$ & $175(27.1)$ & $1.04(0.71-1.50)$ & 0.857 \\
\hline pri-miR-218 rs & E: 0.4264 & & & & \\
\hline Allele & A & $331(57.7)$ & $726(56.2)$ & 1.00 & \\
\hline & G & $243(42.3)$ & $566(43.8)$ & $1.08(0.84-1.38)$ & 0.563 \\
\hline
\end{tabular}


Table 2 Multivariate associations of the pre-miR-27a rs895819 with the risk of Ml (Continued)

\begin{tabular}{|c|c|c|c|c|c|}
\hline \multirow[t]{2}{*}{ Model } & \multirow[t]{2}{*}{ Genotype } & \multirow{2}{*}{$\begin{array}{l}\text { Cases }(n=287) \\
\text { No. }(\%)\end{array}$} & Controls $(n=646)$ & \multirow[t]{2}{*}{ OR $(95 \% \mathrm{Cl})^{a}$} & \multirow[t]{2}{*}{$P^{a}$} \\
\hline & & & No. (\%) & & \\
\hline \multirow[t]{3}{*}{ Genotype } & AA & 85 (29.6) & 199 (30.8) & 1.00 & \\
\hline & $A G$ & $161(56.1)$ & $328(50.8)$ & $1.27(0.87-1.85)$ & 0.213 \\
\hline & GG & $41(14.3)$ & $119(18.4)$ & $1.08(0.65-1.80)$ & 0.771 \\
\hline \multirow[t]{2}{*}{ Dominant } & GG & $41(14.3)$ & 119 (18.4) & 1.00 & \\
\hline & $A G+A A$ & $246(85.7)$ & 527 (81.6) & $1.08(0.69-1.70)$ & 0.744 \\
\hline \multirow[t]{2}{*}{ Recessive } & AA & 85 (29.6) & 199 (30.8) & 1.00 & \\
\hline & $A G+G G$ & $202(70.4)$ & $447(69.2)$ & $1.22(0.85-1.76)$ & 0.273 \\
\hline
\end{tabular}

${ }^{a}$ Adjusted for age, sex, smoking, drinking, hypertension, diabetes and hyperlipidemia

${ }^{b}$ HWE, Hardy-Weinberg equilibrium

Stratified analysis of pre-miR-27a rs895819 polymorphism with the risk of $\mathrm{MI}$

We further evaluated the genotypes and MI susceptibility stratified by age, gender and status of smoking and drinking. As shown in Table 3, except for drinking status $(\mathrm{OR}=0.41)$, the reduced risk associated with AG + AA genotypes was more pronounced among younger $(\mathrm{OR}=0.34,95 \% \mathrm{CI}=0.14-0.88, \quad \mathrm{~Pa}=$ 0.025), male $(\mathrm{OR}=0.28, \quad 95 \% \mathrm{CI}=0.13-0.61, \quad \mathrm{~Pa}=$ $0.001)$ and smoking $(\mathrm{OR}=0.28,95 \% \mathrm{CI}=0.10-0.78$, $P a=0.015)$ subjects.

\section{Multivariate associations of the pre-miR-27a rs895819 polymorphism with the lipid profile}

Since the pre-miR-27a rs895819 polymorphism may exert its effects on MI by regulating lipid metabolism, we further analyzed the association between rs895819 polymorphism and TG, TC, LDL-C and HDL-C levels. Our results found that $\mathrm{AG}$ and AA genotypes of the rs895819 polymorphism conferred about $0.17 \mathrm{mmol} / \mathrm{L}$ and $0.18 \mathrm{mmol} / \mathrm{L}$ increase in HDL-C levels compared to GG genotype (Table 4).

\section{Discussion}

The present case-control study evaluated the potential association between five pri/pre-miRNA polymorphisms and MI susceptibility in a Chinese Han population. Our result showed that the pre-miR-27a rs895819 polymorphism was significantly associated with the MI risk, indicating that $\mathrm{AG}$ and $\mathrm{AA}$ genotypes in pre-miR-27a rs895819 polymorphism might have a protective effect against MI development compared with GG genotype.

Further stratification showed that the protective effect of AG + AA genotype was more remarkable among younger ( $\leq 62$ years old), male and smoking subjects. The potential risk of MI in older subjects is more likely due to the aging effects as weak immune system and relative high-level exposure to environmental risk factors, rather than direct genetic effects. Sex-specific variation in atherosclerosis and CAD has been described $[19,20]$. Hormonal differences, lifestyle, and other metabolism differences between males and females may elucidate our results.

MiR-27a has been reported not only to be an oncogenic miRNA [21], but also regulate lipid metabolism by altering the expression of many lipid metabolism-related

Table 3 Multivariate associations of the pre-miR-27a rs895819 with the risk of Ml by further stratification for age, gender, smoking and drinking

\begin{tabular}{|c|c|c|c|c|c|}
\hline \multirow[t]{3}{*}{ Variables } & \multirow{3}{*}{$\begin{array}{l}\text { Cases/ } \\
\text { controls }\end{array}$} & \multicolumn{2}{|c|}{ Genotype (cases/controls) } & \multirow[t]{3}{*}{$\mathrm{OR}(95 \% \mathrm{Cl})^{\mathrm{a}}$} & \multirow[t]{3}{*}{$p^{a}$} \\
\hline & & $\overline{\mathrm{GG}}$ & $A G+A A$ & & \\
\hline & & №. (\%) & №. (\%) & & \\
\hline \multicolumn{6}{|l|}{ Age } \\
\hline$\leq 62$ & $152 / 341$ & $16 / 14(10.5 / 4.1)$ & 136/327 (89.5/95.9) & $0.34(0.14-0.88)$ & 0.025 \\
\hline \multicolumn{6}{|l|}{ Gender } \\
\hline Male & $222 / 374$ & $22 / 22(9.9 / 5.9)$ & 200/352 (90.1/94.1) & $0.28(0.13-0.61)$ & 0.001 \\
\hline \multicolumn{6}{|l|}{ Smoking } \\
\hline Yes & $171 / 164$ & 18/8 (10.5/4.9) & 153/156 (89.5/95.1) & $0.28(0.10-0.78)$ & 0.015 \\
\hline \multicolumn{6}{|l|}{ Drinking } \\
\hline No & $210 / 555$ & $24 / 35(11.4 / 6.3)$ & $186 / 520(88.6 / 93.7)$ & $0.41(0.22-0.77)$ & 0.006 \\
\hline
\end{tabular}

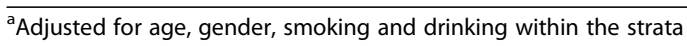


Table 4 ANOVA analysis of the association between pre-miR-27a rs895819 and the TG, TC, LDL-C and HDL-C levels

\begin{tabular}{lllll}
\hline Variable & GG $(n=66)$ & AG $(n=353)$ & AA $(n=514)$ & $P$-value \\
\hline Triglycerides $(\mathrm{mmol} / \mathrm{L})$ & $1.79 \pm 1.30$ & $1.64 \pm 0.85$ & $1.64 \pm 0.86$ & 0.422 \\
Total cholesterol $(\mathrm{mmol} / \mathrm{L})$ & $4.33 \pm 1.27$ & $4.65 \pm 1.15$ & $4.68 \pm 1.16$ & 0.072 \\
$\mathrm{LDL}$ cholesterol $(\mathrm{mmol} / \mathrm{L})$ & $2.70 \pm 0.99$ & $2.76 \pm 0.90$ & $2.77 \pm 0.98$ & 0.875 \\
$\mathrm{HDL}$ cholesterol $(\mathrm{mmol} / \mathrm{L})$ & $1.14 \pm 0.31$ & $1.31 \pm 0.41$ & $1.32 \pm 0.61$ & $\mathbf{0 . 0 3 5}$ \\
\hline
\end{tabular}

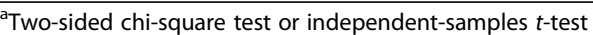

${ }^{\mathrm{b}} P$ values under 0.05 were indicated in bold font

genes [22]. It protected cardiomyocytes from mitochondria-mediated apoptosis during hypoxia/reperfusion injury by targeting IL-10-related pathways [23]. In addition, miR-27a played a unique role in the endothelial cells (ECs) dysfunction, which may contribute to the development of cardiovascular disease such as atherosclerosis, CAD and MI [24]. Urbich et al. has demonstrated that miR-27a promoted angiogenesis by targeting SEMA6A, which induces repulsion of neighboring endothelial cells [25]. Moreover, miR-27a has been shown to be associated with the renin-angiotensin system (RAS) and contribute to modulate the cardiovascular homeostasis and against aortic injury in hypertension by targeting ACE gene [26]. These studies indicate the multiple functions of miR-27a in different pathophysiological states that might be involved in the development and progression of cardiovascular diseases.

The pre-miR-27a rs895819 polymorphism has been reported to be significantly associated with the risk of type-2 diabetes (T2DM) [27] and a variety of cancers [28-30]. The original study can be traced from the time when Yang et al. firstly reported that the G-variant of rs895819 might impair the maturation of the miR-27a and thus, is associated with familial breast cancer risk [31]. Afterwards, GG genotype of this polymorphism was found significantly associated with an increased risk of T2DM in overweight subjects [27]. Here, we enlarge the knowledge of the effect of this polymorphism on human disease. In accordance with these studies, our results suggested that AG and AA genotype decreased the risk of MI, probably because these variants might affect the maturation of the miR-27a as described above, despite the marginal statistical significance of A allele compared with the $\mathrm{G}$ allele in reducing susceptibility of MI (Table 2). To further characterize the functional relevance of the miR-27a polymorphism, we conducted a correlation analysis between the genotypes and the expression of circulating mature miR-27a. However, our data shown that the relative expression of circulating miR-27a was not significantly different when compared the AG or AA genotype with the GG genotype (Additional file 2: Figure S1). Further study is required to clarify the underlying mechanism for this association.
Dysfunction of lipid metabolism is the fundamental pathogenesis of MI. MiR-27a inhibits the expression of many lipid metabolic genes, including FASN, SREBP-1, SREBP-2, PPAR $\alpha$ and PPAR $\gamma$, as well as ApoA1, ApoB100 and ApoE3A [22]. Additionally, a recent review of studies on miRNAs in lipid metabolism has determined that miR-27a may regulate lipid metabolism by reducing lipid synthesis and increasing lipid secretion from cells [32]. Our ANOVA analyses revealed that $A G$ and $A A$ genotypes increase the HDL-C in a significance level compared to GG genotype (Table 4). This result indicated that the mechanism contributing the decreased MI risk of pre-miR27a rs895819 polymorphism might probably due to the elevated HDL-C levels.

Nevertheless, some limitations should be taken into consideration. First, we studied the association between rs895819 and MI risk in a Chinese Han population; further studies in different population are required to verify the true significance of their association. Second, the relatively moderate sample size limited the statistical power of our study. Third, the mechanisms by which the miR-27a and its targets regulate MI occurrence and progression are unknown, additional studies need to be performed prior to functional assessment of the link between rs895819 and MI.

\section{Conclusions}

In conclusion, our findings firstly uncovered that the AG and AA genotypes in pre-miR-27a rs895819 polymorphism were associated with an decreased risk of $\mathrm{MI}$ in a Chinese Han population, and the association was more evident among younger, male and smoking subjects, which potentially due to the elevated HDL-C levels. However, further studies are warranted to confirm the general validity of these findings and to clarify the underlying mechanism for this association.

\section{Additional files}

Additional file 1: Table S1. The sequences of the primers and probes used to genotype the rs895819 polymorphism. (DOCX 89 kb)

Additional file 2: Figure S1. Analysis of circulating mature miR-27a levels in three genotypes of 51 healthy controls. (DOCX 89 kb) 


\section{Abbreviations}

3'UTR: 3' untranslated regions; CAD: Coronary artery disease; FBG: Fasting plasma glucose; HDL-C: High density lipoprotein cholesterol; LDL-C: Low density lipoprotein cholesterol; MI: Myocardial infarction; SNP: single nucleotide polymorphism; TC: Total cholesterol; TG: Triglyceride

\section{Acknowledgements}

Not applicable.

\section{Funding}

The study was supported by grants from the National Natural Science Foundation of China (81370456), the Natural Science Foundation of Guangdong Province (2014A030311015, 2014KZDXM041), the Yangfan Training Program of Guangdong Province (4YF16006G), the Science and Technology Planning Project of Dongguan City (2015108101015,

2013108101057) and the Foundation for Science and Technology Innovation (Climbing Program) in College Students of Guangdong Province (PDJH2016b0217)

\section{Availability of data and materials}

All data generated or analyzed during this study are included in this published article and its supplementary information files.

\section{Authors' contributions}

$\mathrm{M}-\mathrm{yC}$ and JC carried out the statistical analysis, and M-yC drafted the manuscript. JC, M-yZ, L-IL, S-mL, X-sX helped to collect study subjects. SX and $X-d X$ participated in the design of the study. $X L$ and $X-d X$ helped to revise the manuscript. All authors read and approved the final Manuscript.

\section{Ethics approval and consent to participate}

The study was approved and consented by the Medical Ethics Committee of the First People's Hospital of Foshan and the Affiliated Hospital of Guangdong Medical University.

\section{Consent for publication}

All presentations of case reports consent for this publication.

\section{Competing interests}

The authors declare that they have no competing interests.

\section{Publisher's Note}

Springer Nature remains neutral with regard to jurisdictional claims in published maps and institutional affiliations.

\section{Author details}

${ }^{1}$ Institute of Aging Research, Guangdong Medical University, Xin Cheng Avenue 1\#, Songshan Lake, Dongguan 523808, People's Republic of China. ${ }^{2}$ Guangdong Provincial Key Laboratory of Medical Molecular Diagnostics, Guangdong Medical University, Dongguan, People's Republic of China. ${ }^{3}$ Department of Clinical Laboratory, The Affiliated Hospital of Guangdong Medical University, Zhanjiang, China. Institute of Biochemistry \& Molecular Biology, Guangdong Medical University, Zhanjiang, People's Republic of China.

Received: 14 October 2017 Accepted: 27 December 2017 Published online: 06 January 2018

\section{References}

1. Z Zhang XH, Lu ZL, Liu L. Coronary heart disease in China. Heart. 2008;94(9): 1126-31.

2. Yang G, Wang $Y$, Zeng $Y$, Gao GF, Liang X, Zhou M, Wan X, Yu S, Jiang Y, Naghavi M, et al. Rapid health transition in China, 1990-2010: findings from the global burden of disease study 2010. Lancet (London, England). 2013; 381(9882):1987-2015.

3. Li J, Li X, Wang Q, Hu S, Wang Y, Masoudi FA, Spertus JA, Krumholz HM, Jiang L. ST-segment elevation myocardial infarction in China from 2001 to 2011 (the China PEACE-retrospective acute myocardial infarction study): a retrospective analysis of hospital data. Lancet (London, England). 2015 385(9966):441-51.

4. Anand SS, Islam S, Rosengren A, Franzosi MG, Steyn K, Yusufali AH, Keltai M, Diaz R, Rangarajan S, Yusuf S. Risk factors for myocardial infarction in women and men: insights from the INTERHEART study. Eur Heart J. 2008; 29(7):932-40.

5. Lusis AJ. Genetics of atherosclerosis. Trends Genet. 2012;28(6):267-75.

6. Peden JF, Farrall M. Thirty-five common variants for coronary artery disease: the fruits of much collaborative labour. Hum Mol Genet. 2011;20(R2):R198-205.

7. Chacon-Cortes D, Smith RA, Haupt LM, Lea RA, Youl PH, Griffiths LR. Genetic association analysis of miRNA SNPs implicates MIR145 in breast cancer susceptibility. BMC Med Genet. 2015;16:107.

8. Zhang C, Lu J, Liu B, Cui Q, Wang Y. Primate-specific miR-603 is implicated in the risk and pathogenesis of Alzheimer's disease. Aging. 2016;8(2):272-90.

9. Huang S, Lu W, Ge D, Meng N, Li Y, Su L, Zhang S, Zhang Y, Zhao B, Miao J. A new microRNA signal pathway regulated by long noncoding RNA TGFB2OT1 in autophagy and inflammation of vascular endothelial cells. Autophagy. 2015;11(12):2172-83.

10. Nossent AY, Hansen JL, Doggen C, Quax PH, Sheikh SP, Rosendaal FR. SNPs in microRNA binding sites in $3^{\prime}$-UTRs of RAAS genes influence arterial blood pressure and risk of myocardial infarction. Am J Hypertens. 2011;24(9):999-1006.

11. Kim VN, Han J, Siomi MC. Biogenesis of small RNAs in animals. Nat Rev Mol Cell Biol. 2009;10(2):126-39.

12. Kwak PB, Iwasaki S, Tomari Y. The microRNA pathway and cancer. Cancer Sci. 2010;101(11):2309-15.

13. Zhang $M$, Wu JF, Chen WJ, Tang SL, Mo ZC, Tang YY, Li Y, Wang JL, Liu XY, Peng J, et al. MicroRNA-27a/b regulates cellular cholesterol efflux, influx and esterification/hydrolysis in THP-1 macrophages. Atherosclerosis. 2014;234(1):54-64.

14. Zhang Y, Qin W, Zhang L, Wu X, Du N, Hu Y, Li X, Shen N, Xiao D, Zhang H, et al. MicroRNA-26a prevents endothelial cell apoptosis by directly targeting TRPC6 in the setting of atherosclerosis. Sci Rep. 2015:5:9401.

15. Wong LL, Wee AS, Lim JY, Ng JY, Chong JP, Liew OW, Lilyanna S, Martinez EC, Ackers-Johnson MA, Vardy LA, et al. Natriuretic peptide receptor 3 (NPR3) is regulated by microRNA-100. J Mol Cell Cardiol. 2015;82:13-21.

16. Li HY, Zhao X, Liu YZ, Meng Z, Wang D, Yang F, Shi QW. Plasma MicroRNA$126-5 p$ is associated with the complexity and severity of coronary artery disease in patients with stable angina pectoris. Cell Physiol Biochem. 2016; 39(3):837-46.

17. Chen C, Hong H, Chen L, Shi X, Chen Y, Weng Q. Association of microRNA polymorphisms with the risk of myocardial infarction in a Chinese population. Tohoku J Exp Med. 2014;233(2):89-94.

18. Cheng J, Cho M, Cen JM, Cai MY, Xu S, Ma ZW, Liu X, Yang XL, Chen C, Suh $Y$, et al. A TagSNP in SIRT1 gene confers susceptibility to myocardial infarction in a Chinese Han population. PLoS One. 2015;10(2):e0115339.

19. Sayin Kocakap DB, Dogru MT, Simsek V, Cabuk F, Yildirim N, Celik Y, Alyilmaz Bekmez S, Erdem S. The association of paraoxonase 1 gene L55M polymorphism with the extent and severity of coronary artery disease in the Turkish population and its dependence on gender. Anatolian J Cardiol. 2016:16(3):175-82

20. Rios DL, D'Onofrio LO, Cerqueira CC, Bonfim-Silva R, Carvalho HG, SantosFilho A, Galvao-Castro B. Paraoxonase 1 gene polymorphisms in angiographically assessed coronary artery disease: evidence for gender interaction among Brazilians. Clin Chem Lab Med. 2007:45(7):874-8.

21. Mertens-Talcott SU, Chintharlapalli S, Li X, Safe S. The oncogenic microRNA$27 \mathrm{a}$ targets genes that regulate specificity protein transcription factors and the G2-M checkpoint in MDA-MB-231 breast cancer cells. Cancer Res. 2007; 67(22):11001-11.

22. Shirasaki T, Honda M, Shimakami T, Horii R, Yamashita T, Sakai Y, Sakai A, Okada H, Watanabe $\mathrm{R}$, Murakami S, et al. MicroRNA-27a regulates lipid metabolism and inhibits hepatitis C virus replication in human hepatoma cells. J Virol. 2013;87(9):5270-86.

23. Yeh $\mathrm{CH}$, Chen TP, Wang YC, Lin YM, Fang SW. MicroRNA-27a regulates cardiomyocytic apoptosis during cardioplegia-induced cardiac arrest by targeting interleukin 10-related pathways. Shock (Augusta, Ga). 2012; 38(6):607-14.

24. Chistiakov DA, Orekhov AN, Bobryshev YV. The role of miR-126 in embryonic angiogenesis, adult vascular homeostasis, and vascular repair and its alterations in atherosclerotic disease. J Mol Cell Cardiol. 2016:97: 47-55.

25. Urbich C, Kaluza D, Fromel T, Knau A, Bennewitz K, Boon RA, Bonauer A, Doebele C, Boeckel JN, Hergenreider E, et al. MicroRNA-27a/b controls endothelial cell repulsion and angiogenesis by targeting semaphorin 6A. Blood. 2012;119(6):1607-16. 
26. Gu Q, Wang B, Zhang XF, Ma YP, Liu JD, Wang XZ. Contribution of reninangiotensin system to exercise-induced attenuation of aortic remodeling and improvement of endothelial function in spontaneously hypertensive rats. Cardiovasc Pathol. 2014;23(5):298-305.

27. Wang $\Pi$, Chen YJ, Sun LL, Zhang SJ, Zhou ZY, Qiao H. Affection of singlenucleotide polymorphisms in miR-27a, miR-124a, and miR-146a on susceptibility to type 2 diabetes mellitus in Chinese Han people. Chin Med J. 2015;128(4):533-9.

28. Yin Z, Cui Z, Ren Y, Xia L, Wang Q, Zhang Y, He Q, Zhou B. Association between polymorphisms in pre-miRNA genes and risk of lung cancer in a Chinese non-smoking female population. Lung Cancer (Amsterdam, Netherlands). 2016;94:15-21.

29. Bian Q, Chen JJ, Gu JP, Xu J. Association between pre-miR-27a functional polymorphism and risk of colorectal cancer in north Chinese Han population. Oncotargets Ther. 2015;8:3003-7.

30. Qi P, Wang L, Zhou B, Yao WJ, Xu S, Zhou Y, Xie ZB. Associations of miRNA polymorphisms and expression levels with breast cancer risk in the Chinese population. Genet Mol Res. 2015;14(2):6289-96.

31. Yang R, Schlehe B, Hemminki K, Sutter C, Bugert P, Wappenschmidt B, Volkmann J, Varon R, Weber BH, Niederacher D, et al. A genetic variant in the pre-miR-27a oncogene is associated with a reduced familial breast cancer risk. Breast Cancer Res Treat. 2010;121(3):693-702.

32. Yang Z, Cappello T, Wang L. Emerging role of microRNAs in lipid metabolism. Acta Pharm Sin B. 2015;5(2):145-50.

\section{Submit your next manuscript to BioMed Central and we will help you at every step:}

- We accept pre-submission inquiries

- Our selector tool helps you to find the most relevant journal

- We provide round the clock customer support

- Convenient online submission

- Thorough peer review

- Inclusion in PubMed and all major indexing services

- Maximum visibility for your research

Submit your manuscript at www.biomedcentral.com/submit

) Biomed Central 